\title{
Sublingual hematoma under oral anticoagulants
}

\author{
A. Salmi*, M. Slimani and D. Messaif \\ Department of Medical and Surgical Emergencies, University Hospital Center (Pr.Guerinik), Algiers, Algeria
}

\begin{abstract}
Bleeding complications classic oral anticoagulants are represented by gastrointestinal bleeding, genito urinary and intracranial. However, the hematoma of the language is exceptional. It is reported as spontaneous or induced by a tonguebite, tracheal intubation, but also can be promoted by fibrinolytic therapy. Its location, the hematoma may be responsible for respiratory distress by obstruction of the upper airways, meriting special attention to ensure timely management. We describe the occurrence of language hematoma following an overdose of oral anticoagulants, such acenocoumarol (Sintrom $\left.{ }^{\circledR}\right)$, favored by a small lingual injury in a 71 years old patient admitted for respiratory distress by obstruction of the upper airways, whose evolution was favorable.
\end{abstract}

\section{Introduction}

Oral anticoagulants often prescribed to treat a thromboembolic event or for its prevention. This therapeutic class, which is characterized by a narrow therapeutic index, justified careful monitoring, especially in the first days of his prescription, and in general, very close to patients in whom the bleeding risk is high (especially elderly).

Among the very few complications, exceptional view, reported in the literature, is the sublingual hematoma.

We report this unusual observation lingual hematoma complicating oral anticoagulant therapy, acenocoumarol (Sintrom $\left.{ }^{\circledR}\right)$, occurring in an elderly patient of 71 years.

\section{Case presentation}

A patient 71 years old, treated chronically with acenocoumarol (Sintrom) for three months rather ACFA, hospitalized at the acute inpatient unit for breathing.

Clinical symptoms was marked by the presence of a large hematoma of the language making exams ear, nose and throat impossible, accompanied by difficulty breathing (Figure 1).

Indeed the installation of the hematoma was more or less rapidly, within hours after injury of the tongue. Atadmission, the patient was conscious, with no signs of localization, hemodynamically stable, with a slight difficulty breathing. Laboratory tests were not anomalies, outside an INR to 5. The management was symptomatic, based on the administration of vitamin $\mathrm{K} 10 \mathrm{mg}$ by slow intravenous fresh frozen plasma (FFP) at a dose of $20 \mathrm{ml} / \mathrm{kg}$, by default prothrombin complex concentrate. The evolution was marked by the dramatic regression of the hematoma after 5 days without going to do a tracheotomy, when the recovery of oral feeding and anticoagulant therapy (Figure 2).

\section{Discussion}

The prescription of oral anticoagulants for various reasons (Thromphlébite members, pulmonary embolism, heart valve etc ...) is not devoid of complications, especially bleeding, warranting careful monitoring. The significant frequency and prognosis often severe bleeding under Vitamin $\mathrm{K}$ antagonist (VKA) make a dramatic event with an annual incidence of fatal bleeding of $1 \%$ [1-3]. These hemorrhages occur during a dosing error, poor laboratory monitoring, drug interference (quinidine, antibiotics ...) [4,5], or due to trauma, even minimal, as the case of our patient, who, after a bite of his tongue, a large hematoma was quickly installed. The underestimation of the lesion was originally a consultative delay, lack of information on the evolving risk of injury. However, the presence of a language must be proven bite fear the appearance of a hematoma. Monitoring must be careful in order to intervene in case of obstruction of the upper airway, which can only be achieved by consultation and fast antagonism.

Other language bruising episodes have been described in literature.

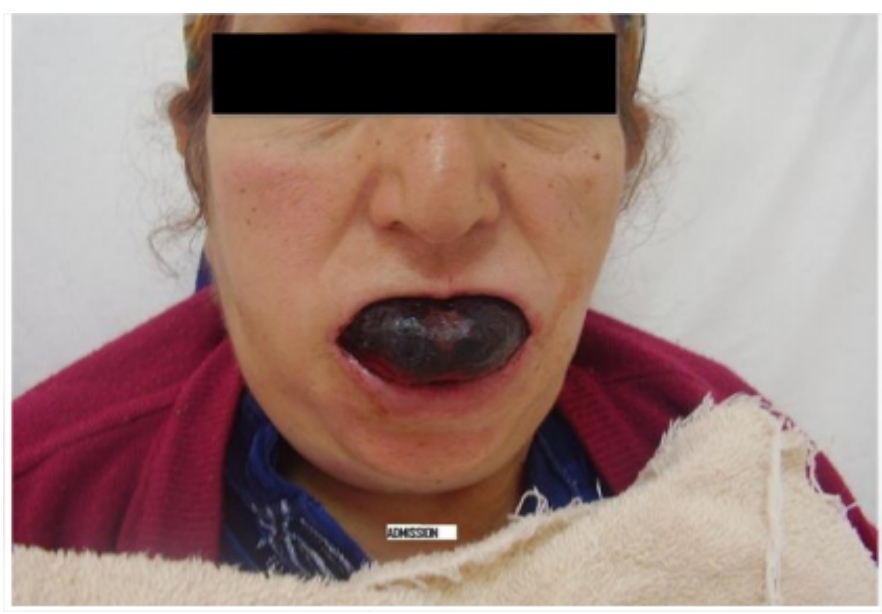

Figure 1. Large hematoma of the tongue, a few hours after the tonguebite.

Correspondence to: Amine Salmi, Professor Department of Medical and Surgical Emergencies, University Hospital Center Mustapha, Algiers, Algeria; E-mail: salmi_amine@yahoo.fr

Key words: oral anticoagulants, bruising of the tongue, acute respiratory distress

Received: July 14, 2015; Accepted: August 21, 2015; Published: August 24, 2015 


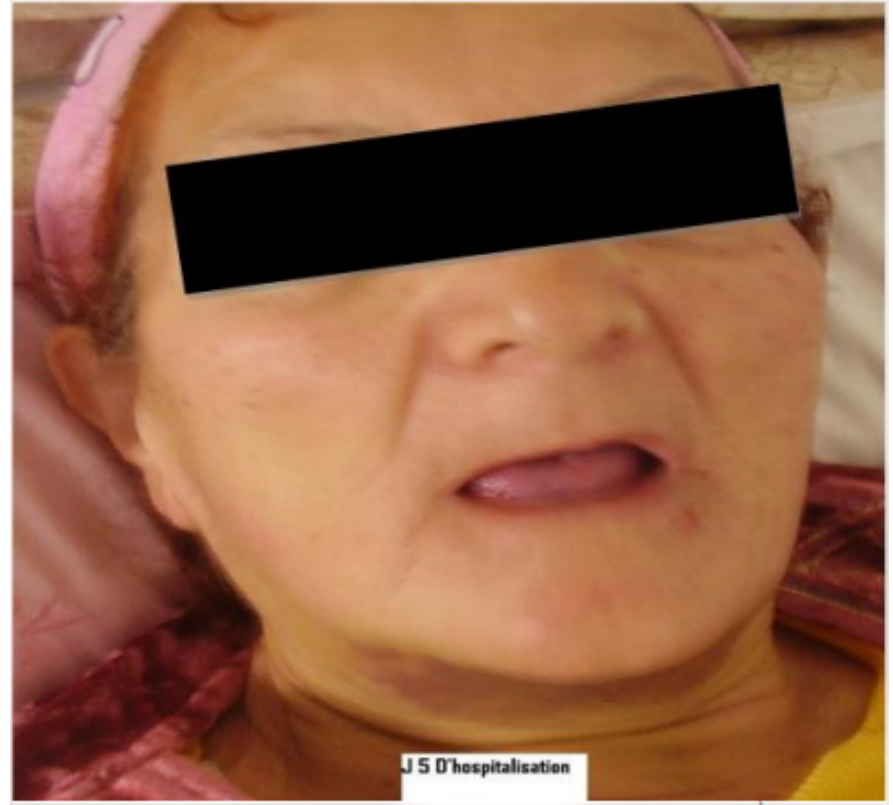

Figure 2. Regression Language hematoma five days after his admission.

These include two cases reported after use of Alteplase [6,7], another with streptokinase with obstruction of the upper airway that required nasotracheal intubation [8], and two others in intubated patients in the aftermath of thrombolysis $[9,10]$.

In an article published in 1979 [11], three patients had respiratory distress following a retro-pharyngeal and submandibular hematoma and one case of obstruction of the upper airway lingual hematoma in a patient with heparin has been published in 1999 [12]. Another case of sublingual hematoma was published in 2012 in a patient of 71 years under antivitamins occurred after dental trauma [13].

\section{Conclusion}

Even though it is rare, this complication deserves special attention, as long as the prognosis is directly related to the precocity of antagonizing and rigorous monitoring of the upper airways, in order to intervene in case of obstruction. The eduction of patients on oral anticoagulants is an essential step in order to minimize the management of time, for quick reference, and thus prompt management.

\section{References}

1. Delerme S. Accidents des traitements anticoagulants oraux. EMC - Médecined'urgence 2011:1-6 [Article 25-190-B-10].

2. Haute Autorité de Santé (2008) Good management practices for oral anticoagulant overdose, situations of hemorrhagic risk and hemorrhagic events in patients taking oral anticoagulants in the ambulatory and hospital setting--April 2008. J Mal Vasc 33: 202213. [Crossref]

3. 3.Elalamy I (2007) Accidents des traitements anticoagulants oraux; EMC (Elsevier Masson SAS,

4. Paris). MédecineD’urgence 25-190-B-10

5. González-García R, Schoendorff G, Muñoz-Guerra MF, Rodríguez-Campo FJ, NavalGías L, et al. (2006) Upper airway obstruction by sublingual hematoma: a complication of anticoagulation therapy with acenocoumarol. Am J Otolaryngol 27: 129-132. [Crossref]

6. Gooder P, Henry R (1980) Impending asphyxia induced by anticoagulant therapy. $J$ Laryngol Otol 94: 347-352. [Crossref]

7. Kounis NG, Zarras GM, Frangides C, Andreas A (1996) Lingual haematoma after treatment with alteplase (recombinant tissue plasminogen activator) for acute myocardial infarction. Heart 75: 427. [Crossref]

8. McMechan SR, Morrow B, Campbell NP (1995) Lingual haematoma after treatmen with alteplase (recombinant tissue plasminogen activator) for acute myocardial infarction. Br Heart J 74: 205.

9. Williams PJ, Jani P, McGlashan J (1994) Lingual haematoma following treatment with streptokinase and heparin; anaesthetic management. Anaesthesia 49: 417-418. [Crossref]

10. Eggers KA, Mason NP (1994) Lingual haematoma following streptokinase therapy. Anaesthesia 49: 922. [Crossref]

11. Eliashar R, Goldfarb A, Nahir M, Sichel JY (2002) Massive tongue hematoma and epistaxis as a complication of anticoagulation and thrombolytic therapies. $J$ Trauma 53: 805. [Crossref]

12. 11.Rosenbaum L, Thurman P, Krantz SB (1979) Upper airway obstruction as a complication of oral anticoagulation therapy. Report of three cases. Arch Intern Med 139: 1151-1153. [Crossref]

13. Kaynar AM, Bhavani-Shankar K, Mushlin PS (1999) Lingual hematoma as a potential cause of upper airway obstruction. Anesth Analg 89: 1573-1575. [Crossref]

14. Puri A, Nusrath MA, Harinathan D, Lyall J (2012) Massive sublingual hematoma secondary to anticoagulant therapy complicated by a traumatic denture: a case report. $J$ Med Case Rep 6: 105. [Crossref]

Copyright: (C2015 Salmi A. This is an open-access article distributed under the terms of the Creative Commons Attribution License, which permits unrestricted use, distribution, and reproduction in any medium, provided the original author and source are credited. 